\title{
Trabalhonecessário
}

ISSN: 1808 - 799X

ANO 12, № 19 - 2014

\section{REUNI: A CONTRARREFORMA DO ENSINO SUPERIOR EM TEMPOS DE CRISE DO CAPITAL E A REALIDADE DA UFF.}

Matheus Castro da Silva ${ }^{1}$

\section{RESUMO}

Este estudo tem como objetivo analisar de que maneira o REUNI (Decreto $\mathrm{n}^{\circ}$ 6.096 , de 24 de abril de 2007), implantado pelo Governo do Partido dos Trabalhadores, se insere em um contexto de crise do capitalismo. Tendo o materialismo histórico e dialético como base metodológica para a realização desta pesquisa, partiremos da discussão acerca da inserção do Brasil na totalidade do Modo de Produção Capitalista, que, segundo Ruy Marini, é de uma maneira dependente. Mediante isso, traremos à baila como essa inserção se materializa nas políticas públicas adotadas pelo Governo brasileiro, neste caso, a Reforma Universitária implementada em 2007. A análise desse processo se justifica sobretudo após vivenciarmos, no ano de 2012, uma greve histórica que atingiu os três setores da Universidade: alunos, técnicos e professores, e o fato de isso ter ocorrido ao final do processo de implementação dessa Reforma. Para tanto, utilizaremos a UFF como nosso campo empírico de pesquisa, para entendermos de que maneira a referida reforma se materializou.

PALAVRAS CHAVE: Crise do capital, Reforma Universitária, Capitalismo dependente.

\begin{abstract}
This study aims to investigate how the REUNI, Decree number 6.096, of April 24 of 2007, implemented by the Workers Party, is inserted in context of the crisis of capitalism. Having the historical and dialectical materialism as a methodological basis for this search, we'll start from the discussion about the inclusion of Brazil in totality of the Capitalist Mode of Production, which, according to Ruy Mauro Marini, is in a dependent way. By this, we'll bring the
\end{abstract}

\footnotetext{
${ }^{1}$ Cursando Mestrado em Educação na Universidade Federal Fluminense; Professor da Educação Básica na rede municipal de Nova Iguaçu. Email: matheusefufrj@hotmail.com
} 


\section{Trabalhonecessário}

ISSN: 1808 - 799X

ANO 12, № 19 - 2014

discussion about how this inclusion is imbodied in public policy adopted by the Brazilian government, in this case, the University Reforma implemented in 2007. The analysis of this process is justified, especially after we've experienced, at 2012, a historical strike that hit all sectors in the university: students, teachers and servers, and the fact this occurred at the end of the deployment process of the reform. Therefore, we will take UFF as our empirical field to understand the way that this reform has materialized.

Keywords: Capitalism crisis, University Reform, Dependent Capitalism.

\section{Introdução}

No Brasil, vivemos um intenso período de mobilizações nos meses de junho e julho de 2013, que ficou conhecido como as "Jornadas de Junho e Julho", em que a população foi às ruas para reivindicar temas diversos como a mobilidade urbana, o estopim desse processo, serviços públicos como saúde, educação e, também, mudanças políticas no país. Todavia, esse processo não aconteceu "do nada", já que em 2012 passamos por um grande período de mobilizações, marcado pela greve dos servidores federais, principalmente pela greve nas Universidades. Foi um processo de luta desencadeado após os constantes ataques do capital à esfera dos serviços públicos, em especial a educação pública, por meio das políticas estatais, principalmente o REUNI (Decreto $\mathrm{n}^{\circ}$ 6.096, de 24 de abril de 2007), o carro chefe das políticas para o Ensino Superior do Governo do Partido dos Trabalhadores (PT).

Esse movimento de ataque aos serviços públicos, sobretudo à educação, é um movimento que já vinha sendo realizado pelo capital, mas agora se intensifica em virtude da crise deste. Desse modo, para cumprirmos o objetivo deste trabalho, a análise do REUNI, em um contexto de crise do capital, é necessário entender a forma pela qual o capitalismo se materializa em nosso país. 


\section{Trabalhonecessário}

ISSN: 1808 - 799X

ANO 12, № 19 - 2014

Nessa análise, utilizaremos a herança teórica formulada por Florestan Fernandes e Ruy Mauro Marini ${ }^{2}$, pois ambos buscaram aplicar o materialismo histórico e dialético para compreender e, por conseguinte, atuar na transformação do capitalismo brasileiro, sem fazer a aplicação de modelos teórico-políticos prontos, derivados de outras realidades, que não possuíam conexão com a realidade brasileira. Para tanto, nosso campo empírico será a Universidade Federal Fluminense (UFF), buscando entender a forma pelo qual o REUNI se materializa nesta Universidade, e como ocorre a relação entre educação e capitalismo na ótica da dependência em tempos de crise do capital.

\section{A particularidade brasileira e o capitalismo dependente: o método de Marx e sua aplicação à realidade brasileira.}

Entendemos que investigar a particularidade do capitalismo no Brasil requer a aplicação do materialismo histórico e dialético com o rigor necessário, porquanto a maneira pela qual ganha corpo o Modo de Produção Capitalista (MPC) na particularidade brasileira é diferente da forma pela qual ele se desenvolveu historicamente nos países considerados desenvolvidos. Para analisar o capitalismo nas sociedades dependentes, mais especificamente no caso brasileiro

\footnotetext{
é preciso colocar em seu lugar o modelo concreto do capitalismo que irrompeu e vingou na América Latina, o qual lança suas raízes na crise do antigo sistema colonial e extrai seus dinamismos organizatórios e evolutivos, simultaneamente, da incorporação econômica, tecnológica e institucional a
}

\footnotetext{
${ }^{2}$ Consideramos as colaborações de ambos como valiosíssimas para o entendimento da realidade brasileira. Apesar de comungarmos mais com as colaborações de Ruy Mauro Marini, sobretudo no que tange à expressão política de suas análises, entendemos que Florestan Fernandes também é fundamental para entender o dilema educacional de um país de capitalismo dependente.
} 


\section{Trabalhonecessário}

ISSN: 1808 - 799X

ANO 12, № 19 - 2014

sucessivas nações capitalistas hegemônicas e do crescimento interno de uma economia de mercado capitalista (FERNANDES, 2009, pp. 51-52).

É importante constatar que Marx e Engels (2008, p. 11) afirmam que o desenvolvimento global do MPC só se desenrolou dessa forma, principalmente nos países centrais, em virtude da inserção subordinada dos países que de alguma forma se constituíram em colônias por meio da expansão do capitalismo, "a grande indústria criou o mercado mundial, preparado pela descoberta da América. O mercado mundial promoveu um desenvolvimento incomensurável do comércio, da navegação e das comunicações".

Esse processo de incorporação de forma colonial à ordem capitalista mundial teve consequências para o Brasil no que tange ao seu processo de desenvolvimento econômico, social, político e cultural, porque ele se constituiu em uma nação satélite do núcleo capitalista, dependendo dos impulsos advindos deste núcleo para que pudessem ocorrer os avanços na ordem socioeconômica local. Contudo, esses impulsos não eram absorvidos de forma unilateral, ainda passavam pelas mediações da ordem sociometabólica local, uma ordem estamental, conservadora e escravista (FERNANDES, 1968). Assim, o desenvolvimento da ordem capitalista no Brasil não ocorre por uma exploração direcionada de fora, na qual as elites locais seriam vítimas, mas com essas mesmas elites sendo também beneficiárias dessa situação de dependência.

A partir da expansão comercial do século $\mathrm{XVI}$, vemos a América Latina acompanhar o capitalismo internacional que se formava, inserindo-se no mercado global com base na produção de metais e gêneros exóticos, engendrando o aumento das mercadorias em circulação e dos meios de pagamento. Destarte, houve a possibilidade de os capitais comercial e bancário 


\title{
Trabalhonecessário
}

ISSN: 1808 - 799X

ANO 12, № 19 - 2014

se desenvolverem assim como houve o sustento da produção manufatureira, permitindo o crescimento da grande indústria.

\begin{abstract}
No caso da industrialização europeia, o recurso à simples produção agrícola interna teria bloqueado a elevada especialização produtiva que a grande indústria tornava possível. O forte incremento da classe operária industrial e, em geral, da população urbana ocupada na indústria e nos serviços, que se verifica nos países industriais no século passado, não poderia ter acontecido se estes não contassem com os meios de subsistência de origem agropecuária, proporcionados de forma considerável pelos países latinoamericanos. Isso foi o que permitiu aprofundar a divisão do trabalho e especializar os países industriais como produtores mundiais de manufaturas (MARINI, 1973, pp. 136-137).
\end{abstract}

Nessa concepção, a implementação da educação superior no Brasil remete aos anos de 1550, quando foi criada de forma não institucionalizada pela Companhia de Jesus, com o intuito de elaboração de seus quadros.

\footnotetext{
Nesses primeiros tempos, a dinâmica reprodutiva da sociedade colonial não demandava um sistema de ensino comprometido em formar indivíduos dotados do saber e da ciência que os pudesse preparar para o exercício de qualquer tipo de autonomia intelectual (MINTO, 2011, p. 103).
}

E no funcionamento da estrutura jesuítica prevaleceu a lógica dos negócios coloniais, não interferindo nos interesses e negócios de Portugal, por também serem grandes beneficiários do regime escravista e da exploração indígena, administrando latifúndios monocultores.

No fim do período colonial, transição do século XVIII para o século XIX, houve a criação das escolas profissionalizantes em áreas tradicionais (medicina, engenharia e direito) por conta da vinda da Coroa Portuguesa para - Brasil, cuja formação em nível superior concorria para a construção da classe dominante brasileira. Era, e ainda é, uma educação pautada na conservação de classes no processo de adequação do país aos processos mais avançados 


\section{Trabalhonecessário}

ISSN: 1808 - 799X

ANO 12, № 19 - 2014

do desenvolvimento do MPC internacional. Conquanto fosse um ensino realizado no interior do país, ele possuía a função de fazer a ligação entre o desenvolvimento interior da civilização e o fluxo do saber importado e acabado (FERNANDES, 1968)

Essa "demora" ocorreu muito por conta da política da Coroa Portuguesa que impedia a criação de universidades aqui no Brasil para evitar a "contaminação" dos brasileiros com o ideário liberal e nacionalista que circulava na época. A esse fato articula-se uma elite que poderia realizar a educação de seus filhos no exterior, majoritariamente em Portugal, onde havia um misto das ideias antiliberais burguesas e as ideias liberais que rondavam a Europa, e também relações de trabalho e um grau de desenvolvimento das forças produtivas que dispensava maiores investimentos na área da educação. Por fim, criavam-se cargos para a prestação de serviços imediatos à Coroa Portuguesa que aqui desembarcava, como a preparação para os serviços burocráticos, médicos acostumados com as doenças locais e engenheiros para dirigir um insipiente processo de urbanização (MINTO, 2011; FERNANDES, 1968).

Se, por um lado, a transferência da Corte não colocava novas bases materiais no processo produtivo nem direcionava mudanças nas estruturas sociais, culturais e históricas, por outro lado, essa transferência acarretava um acirramento nas contradições da estrutura social e econômica, possibilitando uma maior margem para mudanças que traziam consigo novas instituições, hábitos e valores. No entanto, esse processo ocorria por meio da determinação da direção dos padrões e instituições transplantadas, da limitação da modernização e da sua utilização para o aperfeiçoamento da ordem vigente, algo que não está muito distante do que vivemos atualmente. "Sob esse aspecto, a transplantação de instituições da sociedade metropolitana esbarrava 


\section{Trabalhonecessário}

ISSN: 1808 - 799X

ANO 12, № 19 - 2014

em um vazio histórico, que era criado pela própria estrutura social de uma sociedade colonial escravista e senhorial" (FERNANDES, 2004, p. 281).

Seja por conta das pressões da Inglaterra, seja pela própria lógica capitalista, na qual o trabalhador assalariado seria mais "barato" do que o escravo para a obtenção de lucros, observamos o início do fim da escravidão no Brasil a partir da segunda metade do século XIX. No entanto, não se alteraram as bases da economia, que permaneceu com 0 foco na agroexportação, atuando para abastecer os grandes centros do capital de alimentos, no caso, bens-salários ${ }^{3}$, e também de matérias-primas, permitindo aos grandes centros concentrarem sua produção no setor manufatureiro e em seguida industrial.

Entretanto, o aumento da oferta de alimentos e matéria-prima ocorre de modo a desvalorizar a sua participação no mercado, com a deterioração dos seus termos de troca se colocados em conta os produtos manufaturados e, posteriormente, industrializados, ou seja, que contam em sua produção com maior participação da tecnologia. Contudo, como o centro capitalista demandava esses produtos, o que aumentou com a Revolução Industrial, ampliou-se a sua produção, mesmo que isso servisse para baratear ainda mais os produtos. Dessa feita, as elites locais "procuram compensar a perda de renda gerada pelo comércio internacional por meio do recurso de uma maior exploração do trabalhador" (MARINI, 1973, p. 147). Essa maior exploração do trabalhador consistia de: aumento da intensidade do trabalho; prolongação da jornada de trabalho e, por fim, a redução do consumo do trabalhador abaixo do que seria "normal", em que o fundo necessário se converte em fundo de acumulação. A articulação desses três fatores constitui o que Ruy Mauro Marini (1973) entende por superexploração do trabalho.

\footnotetext{
${ }^{3}$ Bens-salários: são os produtos consumidos pelo trabalhador para a reposição de sua força de trabalho. Ler mais em Marx, 2011.
} 


\section{Trabalhonecessário}

ISSN: 1808 - 799X

ANO 12, № 19 - 2014

O processo de industrialização da América Latina ocorre da mesma forma, débil e subordinado aos impulsos do centro hegemônico do capital. A elevação da margem de lucro se dá em virtude de ações como o monopólio, baixa especialização, e as barreiras alfandegárias. Além disso, mediante o baixo desenvolvimento tecnológico, o preço das mercadorias é determinado principalmente pelo salário, logo, o capitalista se aproveita do exército de reserva gerado para pressionar para baixo os salários dos trabalhadores, assim, além da chance de se obter uma alta lucratividade, era a oportunidade de importar a tecnologia que já se encontrava obsoleta no centro do capital.

Esse processo inicial da industrialização correspondia com a necessidade de elevar o grau de instrução da população, aumentar a mão de obra qualificada, e, com isso, expandir a educação formal. Nesse sentido, o início da industrialização também conta com o início da formação de um operariado, incluindo a mão de obra estrangeira, mais acostumada com as lutas sindicais, e, assim, se dá a formação de uma classe trabalhadora que passa a exigir mais direitos. A educação se torna uma bandeira histórica, sobretudo o ensino superior, ainda praticamente inacessível para os seus componentes. Nesse contexto, há a criação das primeiras universidades no país, a maioria compondo o que conhecemos por "Universidades

Conglomeradas", de acordo com Florestan Fernandes, que assim as denominava em virtude de ser uma junção de diversas faculdades isoladas sem que houvesse de fato uma articulação entre elas no processo de produção de conhecimentos. (FERNANDES, 2004; MARINI, 1973)

Assim como a indústria brasileira dependia do processo de transplantação de tecnologia, a Universidade brasileira também se constituía em um polo de adaptação dos conhecimentos advindos do centro do capital, sem que houvesse no processo de sua criação a intenção de se constituir um 


\section{Trabalhonecessário}

ISSN: 1808 - 799X

ANO 12, № 19 - 2014

lócus de um desenvolvimento autônomo e crítico. No entanto, seja por conta do envolvimento de alguns intelectuais, seja por conta da ampliação da participação da classe trabalhadora na Universidade, ainda que limitada a segmentos mais abastados, esta se constituiu em um amplo espaço de embates teóricos e políticos da luta de classes. É a tentativa de a burguesia brasileira, ainda que com pequenas concessões, manter o seu domínio, mesmo que para isso sacrifique qualquer perspectiva de progresso ou desenvolvimento local. (FERNANDES, 2004).

O caráter específico da nossa revolução burguesa cria determinações que inibem/neutralizam o potencial indutor de transformações políticas, econômicas, sociais e culturais irradiadas a partir da dominação burguesa "nacional" ou "interna". Esta, ao contrário, precisa manter a todo custo estruturas econômicas, de poder e de dominação "arcaicas" para compelir permanentemente as forças sociais criadas pelo desenvolvimento das forças produtivas (MINTO, 2011, p. 102).

\section{Crise estrutural do capitalismo e Governo PT}

O MPC é um sistema fundado em contradições, sendo a principal delas a contradição entre capital e trabalho, ou seja, entre os interesses dos capitalistas e os interesses da classe trabalhadora, em que estes se colocam contra os outros antagonicamente. Nessa perspectiva, há momentos em que essas contradições chegam a um ponto limite. Nem os capitalistas nem a classe trabalhadora conseguem se manter nas condições atuais de vida, o que constitui os momentos de crise estrutural do capital. Sendo assim, podemos indicar que

são as contradições do capitalismo contemporâneo que provocaram a atual crise estrutural no processo de acumulação do capital. E o capitalismo contemporâneo, a lógica de seu processo de acumulação, é, por sua vez, consequência das formas como ele próprio saiu de sua última - antes desta - crise estrutural (CARCA- 


\section{Trabalhonecessário}

ISSN: 1808 - 799X

ANO 12, № 19 - 2014

(NHOLO, 2011, p. 73).

Tendo em vista que a última crise, que data dos anos 1970, resultou de uma combinação entre superprodução e queda da taxa de lucro, havia uma grande massa de capital acumulado sem ter aonde ser investido e dar o retorno em manutenção e ampliação da taxa de lucro. A resposta do MPC para conseguir manter a taxa de crescimento da acumulação de capital colocou as formas do capitalismo atual: reestruturação produtiva, que diminui o tempo de rotação de capital; reestruturação do mercado de trabalho, que amplia a extração de mais-valia, no centro e na periferia; crescimento da exploração dos países periféricos pelos países centrais, seja pela remessa de divisas, com juros e serviços da dívida externa, seja pela concorrência interna; expansão dos mercados. (CARCANHOLO, 2011).

Destarte, há a configuração do que entendemos ser o período neoliberal. Como ações de um modelo neoliberal capitalista temos: desmonte dos direitos trabalhistas e sociais conquistados pelos trabalhadores durante o período desenvolvimentista; mercadorização de serviços como saúde, educação e previdência, atendendo de modo variado a algumas frações da burguesia e fortalecimento de uma burguesia de serviços, beneficiária do recuo do Estado nos serviços básicos, reduzindo-se os gastos sociais atendendo às demandas do capital financeiro. (BOITO JÚNIOR, 2005).

Nesse sentido, o Governo PT, que assumiu a presidência da república em janeiro de 2003, cumpre um papel fundamental para a manutenção e reprodução do sistema capitalista. Tendo como carro chefe de suas políticas o Programa de Aceleração do Crescimento (PAC), que tem seu eixo maior nas Parcerias Público-Privadas (PPPs), há um mascaramento no processo de contrarreforma do Estado, calcado na privatização. O discurso do Governo coloca a importância estratégica do sistema de "compartilhamento e conces- 


\section{Trabalhonecessário}

ISSN: 1808 - 799X

ANO 12, № 19 - 2014

sões", no qual o objetivo é privatizar desde os serviços sociais como saúde e educação, até mesmo as maiores riquezas naturais brasileiras, como o recémocorrido "Leilão de Libras"4.

Outrossim, a massa de capital superacumulado necessita de maiores espaços para a sua aplicação, o que gera, não ocasionalmente, os discursos de privatização do Estado, "com maiores privatizações, reduções dos gastos públicos em rubricas de cunho social e aprofundamento das reformas previdenciárias. Trata-se de criar/expandir mercados para a atuação desses capitais sobrantes" (CARCANHOLO, 2011, p. 81). Com isso, a privatização dos espaços estatais e dos serviços sociais corresponde aos anseios do capital em tempos de crise, porquanto há cada vez mais expansão de áreas de investimento para o capital, que atua cada vez mais em todos os setores da existência humana como a cultura, a saúde, e, no nosso objeto de estudo, a educação.

Há, também, o processo de cooptação de entidades históricas da classe trabalhadora por parte do Governo do PT, como a União Nacional dos Estudantes (UNE) e a Central Única dos Trabalhadores (CUT), seu braço no processo de desmobilização do movimento sindical, para arrefecer os choques de classe e ainda granjear algum tipo de apoio às políticas realizadas.

Infelizmente a chegada do PT ao governo federal em 2003, longe de contribuir para minar a hegemonia neoliberal, como todos esperavam,

\footnotetext{
4 "O leilão do Campo de Libra, na Bacia de Campos, que ocorre nesta segunda-feira (21), será a primeira rodada de disputas realizada para conceder, sob o regime de partilha de produção, áreas para exploração de petróleo e gás natural na região brasileira do pré-sal. Cinco anos após a descoberta, o governo coloca em marcha a exploração do petróleo de acordo com o novo regime de partilha. O primeiro leilão será no Rio de Janeiro e nele será ofertado o gigantesco campo de Libra, cujo potencial de óleo recuperável pode se aproximar dos 12 bilhões de barris". Disponível em: http://www.otempo.com.br/capa/brasil/entenda-oleil\%C3\%A3o-de-libra-o-maior-campo-de-petr\%C3\%B3leo-do-brasil-1.734163.
} 


\section{Trabalhonecessário}

ISSN: 1808 - 799X

ANO 12, № 19 - 2014

reforçou-a de modo significativo. A adoção pelo governo petista de uma política macroeconômica abertamente neoliberal - e a cooptação para esta política de importantes movimentos sociais ou, pelo menos, a neutralização da maioria deles - desarmou as resistência ao modelo liberal-corporativo e abriu assim caminho para uma maior e mais estável consolidação da hegemonia neoliberal entre nós (COUTINHO, 2006, p. 193).

Além das políticas privatistas já pautadas, o Governo PT ampliou o processo de transferência de renda do fundo público para o fundo privado, sobretudo com os seguidos cortes orçamentários nos serviços sociais como educação, saúde, habitação, em prol do direcionamento de verbas para o pagamento da dívida e dos serviços da dívida pública, e, é imperioso levar em conta que, em virtude desses cortes, houve maior volume de verbas para o investimento de políticas focais, como o "Bolsa Família", o que também, para nós, se constitui no aprofundamento das políticas neoliberais porque objetiva a diminuição da miséria para obtenção de apoio das massas despossuídas e, logo, amortecer os choques de classe.

Dessa feita, vemos como a educação torna-se ainda mais fundamental para o capital, pois, além do seu forte componente ideológico, uma verdadeira "educação das massas" com a propagação da ideologia burguesa, há a abertura de maiores espaços para a atuação do capital, seja pela entrada nos espaços públicos, seja pela ampliação da rede de educação privada.

\section{REUNI: o Ensino Superior na dependência em tempos de crise do capital.}

Primeiramente, é fundamental colocarmos o que entendemos ser 0 papel da educação, sobretudo da Universidade, em uma sociedade de capitalismo dependente. Como já foi colocado, o controle do desenvolvimento no processo de produção conhecimento e no avanço técnico-científico nos paí- 


\title{
Trabalhonecessário
}

ISSN: 1808 - 799X

ANO 12, № 19 - 2014

ses periféricos é fundamental para a perpetuação da situação de dependência que beneficia as burguesias hegemônicas, assim como a burguesia brasileira. Assim, não há a perspectiva da produção de um conhecimento que possa gerar um processo de desenvolvimento em novas bases materiais, sem que colida com a situação de dependência e subordinação.

\begin{abstract}
As universidades, os centros de pesquisa e os serviços de aplicação ou de tecnologia, como estão organizados atualmente, não se ajustam a essa função. Moldados pelos valores, pelos modelos e pelos fins que prevalecem em instituições análogas nas nações hegemônicas, ignoram ou negligenciam essa necessidade (FERNANDES, 2009, p. 129).
\end{abstract}

Ocorre, então, a perpetuação do processo que Marini (1973) nos colocou anteriormente. $O$ processo de perpetuação e complexificação da dependência se dá por meio de mecanismos como: a deterioração dos termos de troca entre as mercadorias produzidas com grandes quantidades de tecnologia, no caso do centro do capitalismo, e as mercadorias produzidas com um baixo desenvolvimento tecnológico, no caso das nações periféricas; há um componente ideológico do ajustamento à situação de dependência, impossibilitando a produção de um saber crítico, o que é comum tanto no centro do capital, quanto na periferia, pois este colide com a própria estrutura do MPC; priva-se de um mercado que se torna cada vez mais fundamental atualmente, que é o mercado de patentes, no qual, mesmo os saberes aqui produzidos, acabam sendo levados para o exterior, resultando em evasão de divisas que naturalmente seriam brasileiras. Além disso, vivemos em um outro contexto, onde a educação torna-se uma fonte fundamental para o processo de acumulação de capital, e a necessidade de privatização e empresariamento da educação é cada vez maior, sobretudo no contexto vivido de crise do capital. 


\section{Trabalhonecessário}

ISSN: 1808 - 799X

ANO 12, № 19 - 2014

Ao analisarmos as políticas para a educação superior no Brasil após o período Collor, observamos que tais políticas cada vez mais se constituem em ataques à educação pública, gratuita e de qualidade.

O empresariamento da educação superior, que foi iniciado com o governo Collor-Itamar, ganhando nova racionalidade com o governo Cardoso, será aprofundado no governo Lula da Silva a partir de um duplo mecanismo: a ampliação do número de cursos privados e a privatização interna das instituições públicas (LIMA, 2006, p. 38).

A partir desse breve apanhado, podemos fazer a análise da contrarreforma universitária ${ }^{5}$. O REUNI é um programa que surge com a prerrogativa de expansão e democratização do ensino, além de conferir a possibilidade de aumentar a taxa de permanência do aluno na Universidade, ou seja, reduzir os índices de evasão, como afirma o corpo do Decreto.

\footnotetext{
[...] fica instituído o Programa de Apoio a Planos de Reestruturação e Expansão das Universidades Federais - REUNI, com o objetivo de criar condições para a ampliação do acesso e permanência na educação superior, no nível de graduação, pelo melhor aproveitamento da estrutura física e de recursos humanos existentes nas universidades federais (BRASIL, 2007).
}

Reconhecemos que as bandeiras e objetivos acima propagados são históricos e muito caros à classe trabalhadora, no entanto, a maneira como eles foram viabilizados, de forma a atingir os interesses do grande capital constitui um grande problema. Por não garantir um aumento de verbas proporcional ao do número de estudantes, e, às vezes, nem garantir um aumento da dotação orçamentária das IFES, já que esse aumento depende do orçamento do próprio MEC, esse processo de expansão se encontra severamente comprometido.

\footnotetext{
${ }^{5}$ Denominamos contrarreforma universitária, pois, houve a capitulação por parte do Governo PT de bandeiras históricas da classe trabalhadora, como a expansão do Ensino Superior, a democratização e a autonomia universitária, para colocá-las a serviço do capital.
} 


\section{Trabalhonecessário}

ISSN: 1808 - 799X

ANO 12, № 19 - 2014

Tendo como principais objetivos a elevação da taxa de conclusão de curso para $90 \%$ e o aumento da relação entre professor e aluno para 18, o REUNI busca a expansão das matrículas e certificações no Ensino Superior (ES). Para tanto, sem que haja um aumento proporcional nas verbas destinadas ao ES, recomenda-se a otimização do uso da infraestrutura existente, mas que já era insuficiente para a demanda antiga, causada justamente pela falta de investimentos. O Projeto também coloca a importância da redução da evasão, ocupação de vagas ociosas, e aumento das vagas de graduação, sobretudo nos cursos noturnos. No entanto, o MEC ressalta que não se deve adotar um único modelo, mas respeitando a autonomia universitária e as particularidades das IFES, cada uma poderia escolher como fazer, desde que cumprisse as metas nos 5 anos propostos, o que se torna contraditório, pois, há a possibilidade de aumento de apenas $20 \%$ das verbas da IFE.

Dessa forma, se desenrola uma reforma do ensino superior em uma perspectiva mais precarizante do ensino público, seguindo a linha de austeridade fiscal e privatizações recomendadas pelos organismos internacionais.

\footnotetext{
Sobre a base das legislações (incluindo a educacional) que foram dando corpo à reforma do Estado, estabeleceu-se um conjunto de diretrizes para a reforma da educação superior nos moldes das grandes diretrizes dos organismos internacionais para os países em desenvolvimento, bem como adequadas para as realidades específicas de cada país (MINTO, 2011, p. 239).
}

Assim, vemos o processo total de mercadificação da educação, colocando-a de acordo com as normas do mercado: um sistema de avaliação das Universidades e dos docentes em um mote produtivista; aproximação entre o setor privado e as universidades públicas consolidando parcerias para a com- 


\section{Trabalhonecessário}

ISSN: 1808 - 799X

ANO 12, № 19 - 2014

plementação de verbas; configuração do ensino terciário, ou seja, fim do padrão único de Universidade que articulava ensino, pesquisa e extensão; ampliação do número de cursos privados e de privatização interna; alocação de verbas públicas para o setor privado; processo de certificação em larga escala e de aligeiramento da formação, cursos de curta duração, conjunto de alterações na carreira docente, fim da estabilidade e precarização da profissão, contratos e condições de trabalho; mercantilização do ensino e prevalecimento das propostas realizadas pelos organismos internacionais. (LIMA, 2006).

Após esse panorama do REUNI e de suas condições de implementação nas IFES, verificaremos a maneira pela qual esse projeto se materializou na Universidade Federal Fluminense, e as suas consequências para a comunidade acadêmica.

\section{O REUNI na UFF: marcas da precarização.}

O processo de implementação do REUNI na UFF foi muito conturbado, encontrando grande resistência dos três setores da Universidade: o movimento docente, o movimento estudantil e o movimento dos servidores, com especial destaque para os dois primeiros, em uma postura mais combativa ao Governo. Após reuniões do Conselho Universitário altamente confusas, muitas vezes beirando as agressões físicas, vemos a realização da reunião do Conselho que aprovou o REUNI na UFF ocorrer no Palácio da Justiça de Niterói, com a presença da polícia, refletindo que a comunidade acadêmica de fato não desejava o acordo. Para constar, em nível nacional, mais de 20 reitorias se encontravam ocupadas em protesto contra a Reforma Universitária.

Apesar de todas as resistências do movimento estudantil e do movimento docente, a reitoria da UFF encaminhou a proposta de adesão da universidade ao REUNI. Para tal, a reunião do Conselho Universitário realizou-se no Palácio da Justiça de Niterói, sob forte escolta policial, onde estudantes, sindicalistas e conselheiros tiveram 


\section{Trabalhonecessário}

ISSN: 1808 - 799X

ANO 12, № 19 - 2014

barrada a sua entrada. Os policiais militarem usaram spray de pimenta e ameaçaram estudantes e professores de prisão (GTPEADUFF/SSind, 2013, p. 26).

Nesse sentido, observamos que, em virtude da resistência oferecida pela comunidade acadêmica à implementação da REUNI, a UFF foi uma das últimas Universidades a realizar o envio do projeto para o governo.

Todavia, a aprovação do projeto foi a formalização de muitos aspectos que já vinham sendo alterados no interior da própria UFF. No ano de 2004, há a aprovação do Programa de Desenvolvimento Institucional (PDI) da UFF (2004-2007), que tomava como paradigma as mudanças na sociedade, o alto desenvolvimento tecnológico e científico, e como resposta buscava uma ampliação não só do número de cursos e matrículas de graduação e pós, mas, também, da diversidade de se ofertarem esses cursos: cuidar da evasão estudantil, da alta taxa de retenção, cursos noturnos, criar novos cursos. No entanto, é fundamental ressaltar que nesse processo de expansão não estava previsto o aumento correspondente das verbas destinadas à Universidade, o que já fornecia indicativos da provável precarização.

Apesar de preconizar o aumento da democracia e da autonomia universitária, vemos o processo do "chantagismo" que marcou o "acordo" entre UFF e MEC, porquanto a liberação de verbas e a contratação de novos professores se encontravam condicionadas à assinatura do acordo de gestão com o MEC. O documento que trata da adesão da UFF ao REUNI, aprovado em novembro de 2007, considera que a realização de concursos públicos para docentes e técnicos administrativos estará, assim como a distribuição de novas gratificações para cargos comissionados, condicionada à assinatura de um termo de metas entre a UFF e o MEC (GREGÓRIO, 2011, p. 176). 


\section{Trabalhonecessário}

ISSN: 1808 - 799X

ANO 12, № 19 - 2014

Já em 2009, ocorre a elaboração de um novo PDI (2008-2012), já adotando como diretrizes alguns elementos do antigo PDI, e agora incorporando elementos já existentes no REUNI. Esse novo PDI exalta o REUNI, e aponta o Decreto como o responsável por criar condições ideais para a UFF. "[...] Defende a reestruturação curricular, a fim de diminuir a retenção e a evasão estudantil e a criação de novos cursos e turnos noturnos, sempre nos moldes estabelecidos pelo REUNI" (GREGÓRIO, 2011, p. 178).

Coloca-se a importância de adequação às novas tecnologias da educação, sobretudo com os cursos de Ensino à Distância; a reestruturação dos cursos de pós-graduação que se encontram fora dos padrões da CAPES; o foco no ensino noturno; e a abertura de concursos que contemplem a categoria dos professores doutores, o que, de fato, ocorreu em um número reduzidíssimo de vagas, como veremos adiante. Nesse sentido, é importante analisar o Acordo de Metas para a adesão ao REUNI, um contrato de gestão assinado pela UFF e pelo MEC, no qual, como contrapartida à adesão e ao cumprimento das metas, a UFF receberia verbas para realizar seus projetos de reestruturação.

Segundo a ADUFF (2008), até 2011, a UFF terá que realizar um aumento de $106 \%$ no número de matrículas $(254 \%$ no período noturno em relação a 2007) e aumentar o número de concluintes em $228 \%$ (521\% no período noturno), sob pena de ter a transferência de recursos interrompida a qualquer tempo no caso de não cumprimento destas metas, conforme subcláusula $1^{\underline{a}}$ da cláusula $7^{\underline{a}}$ (ADUFF, 2008 apud GREGÓRIO, 2011, p. 179).

Quando analisamos a dotação orçamentária da UFF, há realmente um maior aporte em virtude do REUNI, um aumento de quase $50 \%$. Todavia, indagamo-nos se isso foi o suficiente visto que, no mesmo período, se aumentou o número de cursos de graduação em quase $100 \%$, e os cursos de pós-graduação em $257 \%$. O grande destaque é o aumento de 126\% no número 


\section{Trabalhonecessário}

ISSN: 1808 - 799X

ANO 12, № 19 - 2014

de cursos noturnos de graduação. O percentual do aumento de matrículas foi na casa de $126 \%$, sendo que grande parte desse aumento se concentrou no projeto de interiorização do ensino. Ademais, no período do REUNI, o aumento do número absoluto de docentes se deu na casa dos 30\%, mas se for observado a partir de 1995, o número foi apenas de $14,4 \%$. Isso ocorreu em um período que a Universidade passou por diversos e longos processos de expansão. Como marca disso, vemos que, na UFF, há o acrescimento no quadro docente de cerca de 191 professores, no período entre 1995 e 2010, para um aumento de mais de $20 \mathrm{mil}$ alunos, o que caracteriza a total precarização não apenas da educação, mas também das relações e condições de trabalho (GREGÓRIO, 2011).

A partir do Governo Dilma, a situação da Universidade se deteriora. "Os cortes nos gastos públicos, no ano de 2011, e a proibição de preenchimento das vagas docentes para o REUNI significam um rompimento unilateral do acordo de metas assinado pela reitoria da UFF, em 2007" (GTPEADUFF/Ssind, 2013, p. 27). Contudo, as vagas discentes em relação ao período sofreram um aumento da ordem de 16,33\%, e precisariam ser honradas pelos professores da UFF ${ }^{6}$.

Cerca de 148 vagas docentes previstas para o REUNI 2011 foram canceladas (das quais 85 seriam para os polos do interior) e, em contrapartida, o governo editou a MP № 525 de 14/02/2011 - que altera a Lei № 8.745/93 (posteriormente transformada na Lei № 12.425 de 17/06/2011), criando a figura do professor temporário (professor substituto sem a necessidade de afastamentos ou vacâncias) - e a Portaria MEC № 196 de 24/02/2011, publicada no D.O.U. de 25/02/2011, liberando a contratação de professores temporários para as IFES 'cumprirem sua demanda' para o REUNI no exercício de 2011 (GTPE-ADUFF/Ssind, 2013, p. 27).

\footnotetext{
${ }^{6}$ Os professores da UFF deveriam fazer um "esforço redobrado", conforme afirmava a reitoria no Memo Circular №04/2011 de 09/06/2011 (GTPE-ADUFF/SSind, 2013, p. 27).
} 


\section{Trabalhonecessário}

ISSN: 1808 - 799X

ANO 12, № 19 - 2014

Um outro aspecto importante que devemos ressaltar é o processo de interiorização dos cursos da UFF. Historicamente, a UFF tem na interiorização uma grande marca constitutiva de sua história institucional, algo que se intensificou a partir das expansões de 2003. Os primeiros cursos foram os de Engenharia, em Volta Redonda, e o de Serviço Social, em Campos. Até o presente momento, vemos campi da UFF em Santo Antônio de Pádua, Angra dos Reis, Cabo Frio, Itaperuna, Macaé, Miracema, São João de Meriti, Nova Friburgo, Rio das Ostras e, por fim, a construção de um novo campus em Macaé.

Inicialmente, as unidades eram criadas em parceria com as prefeituras locais, servindo inclusive de "barganha política" entre Governo Federal e as prefeituras.

\footnotetext{
Os investimentos das prefeituras eram fundamentais sobretudo pelas questões de infraestrutura e manutenção. Com o passar do tempo, e do descumprimento de acordos por parte das prefeituras, os custos da interiorização passam a ser cada vez mais centralizados pela UFF e pela União (GTPE-ADUFF/Ssind, 2012, p. 28).
}

Os acordos se davam majoritariamente com relação aos espaços em que os polos universitários e os campi se alocariam, logo, o descumprimento dos mesmos acarretava grandes dificuldades no processo de acomodação das Universidades, além de obstaculizar a sua expansão.

Com a adesão ao REUNI, que possuía a interiorização como uma das bandeiras fundamentais, a UFF passou a se concentrar ainda mais no processo de expansão para o interior de suas atividades. No entanto, sem um aumento correspondente na dotação orçamentária da UFF, sem a ampliação das vagas docentes, esse processo de expansão se deu em uma lógica totalmente precarizante. 


\section{Trabalhonecessário}

ISSN: 1808 - 799X

ANO 12, № 19 - 2014

Os alunos chegaram - E foram bem vindos! -, porém as salas de aula, as bibliotecas, a moradia estudantil, o transporte, o restaurante universitário, os laboratórios, os técnicos e os professores ainda estão em falta. As debilidades estruturais dos Polos são grandes e dificultam a plena atividade de ensino, pesquisa e extensão. Em algumas unidades, diante das perspectivas e promessas iniciais, 0 desânimo chega a tomar conta de estudantes e professores. Com exceção do Polo de Volta Redonda, o único a contar com boas instalações e docentes em número satisfatório, os demais enfrentam déficit de professores, carência de espaço físico, falta de laboratórios e até autoritarismo e assédio moral a professores e estudantes (GTPE-ADUFF/Ssind, 2013, p. 28).

Essa não é a realidade apenas do interior no caso da UFF, onde em Niterói também podemos acompanhar a carência de professores, técnicos e espaço qualificado para que os alunos, docentes e técnicos possam desenvolver as suas atividades. Essa situação é fruto de políticas sucessivas de ataques à educação pública, além do estopim do REUNI, com um processo de expansão altamente desestruturado. Contudo, é notória a diferença que se estabelece entre a unidade da sede as unidades do interior, onde estas possuem menos condições estruturais de desenvolver atividades de pesquisa e extensão, além de possuírem em seus quadros docentes em sua maioria professores substitutos e temporários, que tem por obrigação contratual a realização de atividades de ensino. Assim, constitui-se um processo de hierarquização dentro da própria IFES, que possui unidades de excelência, com ensino, pesquisa e extensão, e unidades que compõem o chamado Ensino Terciário, apenas com atividades de ensino, e, mesmo assim, de forma precarizada.

Outro fator agravante dessa condição é a vinculação entre financiamento e avaliação, o que faz com que as Universidades se subordinem à lógica de mercado para captar recursos extras, por meio da criação de cursos pagos ou estabelecimento de vínculos com o setor privado. 


\section{Trabalhonecessário}

ISSN: 1808 - 799X

ANO 12, № 19 - 2014

investimento que possibilitam a constituição de espaços altamente desenvolvidos e estruturados, ao lado de estruturas precárias e anacrônicas. São investimentos que seguem a lógica da produção do conhecimento para servir aos interesses dos financiadores, sem compromisso com a produção do conhecimento socialmente referenciado (GTPE-ADUFF/Ssind, 2013, p. 37).

O professor assume cada vez mais o caráter do "empreendedor", que deve se vincular aos cursos pagos, concorrer a editais, além de ofertar seus serviços, no caso a sua pesquisa e o processo de produção do conhecimento, à iniciativa privada.

Nesse sentido, vemos a relação entre o REUNI e a crise, porquanto uma das formas de salvar o capital em momentos de crise é a transferência dos fundos públicos, o que se obtém por meio do corte cada vez maior de gastos com serviços sociais, como a educação, além, do processo de abertura para a educação privada, inclusive com a entrada de grandes funções, empresas de capital aberto no ramo educacional.

\section{Conclusão}

Em última análise, entende-se que a última Reforma Universitária coaduna perfeitamente com as demandas do capital em um período de crise estrutural. O processo de ampliação dos cursos, do número de matrículas, dos campi, ao passo que há a redução gradativa das verbas que são investidas na educação pública, abrindo para espaço para ação da iniciativa privada dentro da esfera pública é um dos meios mais comuns de abrir espaço para o processo de ampliação da ação de um capital superacumulado. Não obstante, vemos também o processo de transferência de renda do fundo público para o setor privado por meio de programas como o PROUNI e o FIES, se constituir em dos maiores projetos da história brasileira de privatização da educação.

O processo de privatização interna das IFES fica muito claro quando acompanhamos o processo da produção de pesquisas e extensão, com muitos 


\section{Trabalhonecessário}

ISSN: 1808 - 799X

ANO 12, № 19 - 2014

dos projetos sendo custeados por empresas e outros segmentos do setor privado, onde o conhecimento produzido dentro da Universidade Pública é direcionado ao interesse do empresariado e não da população que a custeia. Com isso, colocam-se duas questões fundamentais: a primeira é a "diminuição" da ação estatal, colocando cada vez mais dinheiro público para as instituições financeiras privadas, uma das maneiras de agir em momentos de crise do capital; e a segunda é a redução de custos das empresas, que, ao invés de terem que gastar em pesquisas e laboratórios para produzirem seus próprios produtos, terceirizam o seu setor de logística e pesquisa, por meio de consultorias com os profissionais do setor público.

Além disso, é fundamental entendermos o processo de certificação em larga escala, em um momento que o emprego no setor formal se encontra em queda, como uma forma de ampliação de um exército de reserva mais qualificado, pressionando para baixo a política salarial da classe trabalhadora, fora a diminuição da capacidade de pressão dos trabalhadores por melhores condições de vida. Ainda nessa lógica, uma educação com cada vez menos qualidade, e a menor participação dos estudantes em atividades de pesquisa e extensão, fazem com que se produza cada vez menos conhecimento crítico, que se choque com as próprias condições de vida gestadas no capitalismo.

Por fim, há a mudança de paradigma na profissão docente, em que o professor deve cada vez mais se subordinar à lógica do mercado, concorrendo a editais, estabelecendo parcerias com empresas, para poder exercer suas atividades de pesquisa e extensão, quebrando a isonomia salarial entre os docentes, e também atuando para fragmentar e fraturar os laços de solidariedade entre os mesmos. É o fomento a uma mentalidade cada vez mais individualista, o que dificulta a organização e mobilização dos interesses coletivos. 


\section{Trabalhonecessário}

ISSN: 1808 - 799X

ANO 12, № 19 - 2014

Contudo, toda essa situação ocorreu em meio a muitas resistências e mobilizações do corpo universitário, em especial o corpo docente, visto a greve de 2012, a maior greve da história do Ensino Superior público brasileiro. Essa greve ocorre em um cenário complexo e até improvável, pois, em meio a todos esses ataques, além da cooptação de entidades caras ao movimento da classe trabalhadora para o lado da burguesia, os docentes, técnicos e alunos, se organizaram e construíram uma greve muito significativa.

\section{Referências.}

BOITO JUNIOR, A. A burguesia no Governo Lula. Crítica Marxista (São Paulo), Rio de Janeiro, v. 21, p. 52-77, 2005.

BRASIL. Presidência da República. Decreto no 6.096, de 24 de abril de 2007. Institui o programa de apoio a planos de reestruturação e expansão das Universidades Federais - Reuni. Diário Oficial da União, Brasília, DF, 25 abr. 2007.

CARCANHOLO, M. Conteúdo e forma da crise atual do capitalismo: lógica, contradições e possibilidades. Crítica e Sociedade: revista de cultura política. Pg 73-84. v.1, n.3, Edição Especial - Dossiê: A crise atual do capitalismo, dez. 2011.

COUTINHO, C.N. O Estado brasileiro: gênese, crise, alternativas. Pg. 173-200. IN: LIMA, J.C.F; NEVES, L.M.W (orgs). Fundamentos da educação escolar do Brasil contemporâneo. Rio de Janeiro: Editora Fiocruz/EPSJV, 2006. FERNANDES, F. Capitalismo dependente e classes sociais na América . Sociedade de classes e subdesenvolvimento. Rio de Janeiro: Zahar Editores, 1968. 


\section{Trabalhonecessário}

ISSN: 1808 - 799X

ANO 12, № 19 - 2014

. Universidade e desenvolvimento. Pg. 272-316. In: IANNI, O.

(org.). Florestan Fernandes: sociologia crítica e militante. São Paulo: Expressão Popular, 2004.

GREGÓRIO, J.R.B. de. Política de pessoal docente no Governo Lula: Uma análise do REUNI na UFF e seus desdobramentos. 2011. 259f. Dissertação (Mestrado em Educação). Faculdade de Educação. UFF, Niterói. 2011.

GTPE-ADUFF/Ssind. Caderno de expansão e condições de trabalho docente. Niterói, 2013.

JORNAL O TEMPO. Entenda o leilão de Libra, o maior campo de petróleo do Brasil. Disponível em: http://www.otempo.com.br/capa/brasil/entenda-oleil\%C3\%A3o-de-libra-o-maior-campo-de-petr\%C3\%B3leo-do-brasil-1.734163. Acesso em: 15/01/2013.

LIMA, K.R. de S. Capitalismo dependente e "Reforma universitária consentida": a contribuição de Florestan Fernandes para a superação dos dilemas educacionais brasileiros. In: SIQUEIRA, A.C. de; NEVES, L.M.W. (orgs). Educação superior: uma reforma em processo. São Paulo: Editora Xamã, 2006.

MARINI, R.M. Dialética da dependência (1973) In: Ruy Mauro Marini vida e obra. STEDILE, J.P.; TRASPADINI, R. (orgs). São Paulo: Expressão Popular, 2011.

MARX, K. Grundrisse. São Paulo: Boitempo; Rio de Janeiro: Editora UFRJ, 2011.

MARX, K.; ENGELS, F. Manifesto do partido comunista. São Paulo: Expressão Popular, 2008.

MINTO, L.W. A educação da "miséria": particularidade capitalista e educação superior no Brasil. 2011. 326f. Tese (Doutorado em Educação). Faculdade de Educação. Unicamp, Campinas. 2011. 


\section{Trabalhonecessário}

ISSN: 1808 - 799X

ANO 12, № 19 - 2014

Recebido em: 31/03/2014

Aprovado em: 10/09/2014 